\title{
INTELECTUALES, REVISTAS Y EDITORIALES EN LA CRISIS DEL FRANQUISMO: EL CASO DE CUADERNOS PARA EL DIÁLOGO Y EDICUSA (1963-1975)
}

\author{
JAVIER Muñoz Soro \\ Universidad Nacional de Educación a Distancia
}

\section{RESUMEN}

En las explicaciones de la transición española a la democracia tras la muerte de Franco siempre han ocupado un lugar fundamental las grandes transformaciones sociales desarrolladas durante la última década de la dictadura. Pero en la historiografía más reciente los factores culturales han ganado visibilidad frente a los socioeconómicos, claves en las interpretaciones funcionalistas de la modernización, y los meramente políticos, que privilegian los relatos históricos basados en el protagonismo de las élites y los actores políticos. En esa emergencia de la sociedad civil, reconstrucción del lenguaje de la democracia y conquista de espacios liberados al control del régimen debe destacarse el papel de numerosas revistas, editoriales y otras empresas culturales que prepararon el camino al cambio político, entre las cuales destacaron la revista Cuadernos para el Diálogo y la editorial Edicusa.

Palabras clave: Franquismo, cambio cultural, revistas, editoriales, Cuadernos para el Diálogo, Edicusa.

\section{ABSTRACT}

The great social transformations that took place in the last decade of the dictatorship have always been considered fundamental to explain Spanish transition to democracy after Franco's death. Yet, most recent historiography concedes to cultural factors more visibility than to socioeconomic aspects, key for a functionalist interpretation of modernisation, or to merely political aspects, which favour a historical interpretation based on the performance of elites and political actors. In the process of reappearance of civil society, of the construction of a new democratic language and of snatching spaces from the control of the regime, magazines, publishing houses 
and other cultural activities played an outstanding role, paving the way for political change. This was the case of the monthly magazine Cuadernos para el Diálogo and of Edicusa publishing house.

Key words: Franco dictatorship, cultural change, magazines, publishing houses, Cuadernos para el Diálogo, Edicusa.

\section{INTRODUCCIÓN: CAMBIO CULTURAL, CAMBIO POLÍTICO}

La liquidación de la dictadura personal más antigua de Europa, testimonio casi arqueológico de otra época, la del ascenso de los fascismos, fue seguida con enorme interés por la prensa internacional, que mostró su admiración por la estabilidad y la relativa ausencia de violencia de la transición española a la democracia bajo la guía de un joven rey. Características éstas que también atrajeron la atención del mundo académico, de muchos historiadores, politólogos y demás científicos sociales tanto dentro como fuera de nuestras fronteras, quienes no tardaron en utilizar el caso español para elaborar modelos y ponerlos en relación con otras transiciones desde regímenes autoritarios que, en oleadas sucesivas, afectaron al sur y este de Europa y la América Latina $^{1}$.

En esos modelos cobraban fuerza otra vez las explicaciones estructurales, funcionalistas y de la modernización tan en boga en los años cincuenta, pero que una terrible sucesión de golpes militares en la década siguiente había desmentido. Ahora, por el contrario, los hechos parecían dar la razón a esa teórica correlación positiva entre crecimiento económico y democracia, entre renta per capita y libertades políticas. Si acaso se ponía algo más el acento en los necesarios requisitos político-culturales, en particular la formación de una cultura cívica y la extensión de un consenso social sin espacio para la violencia de las políticas excluyentes o absolutas. Las grandes transformaciones socioeconómicas de los años sesenta, en particular los cambios sectoriales en la población ocupada, la extensión de una economía neocapitalista, la urbanización o el crecimiento de las clases medias y los funcionarios del Estado habían creado las bases sociales del cambio político ${ }^{2}$. Tanto que, en último término, la transición hacia un sistema homologable a los del entorno europeo occidental habría sido inevitable, por encima de quienes hubieran sido al final los encargados de llevarla a cabo.

Semejante determinismo mecanicista, aunque generalmente no formulado de manera tan explícita, ha sido contestado por numerosos autores que subrayan la frecuencia con que el modelo no se cumple en la realidad histórica empírica. De ahí que en las últimas dos décadas se hayan sucedido diversas reformulaciones que suelen sumar a esas supuestas precondiciones funcionales socioeconómicas, otras de tipo político y cultural igualmente importantes. El modelo original queda así bastante desfigurado, reduciendo el valor explicativo de la variante económica a un factor importante, aunque no suficiente, ni siquiera a veces necesario. En cuanto al requisito

\footnotetext{
TEZANOS, José F.; COTARELO, Ramón y DE BLAS, Andrés, La Transición democrática española, Madrid, Sistema, 1989; LINZ, Juan J., y STEPAN, Alfred C., Problems of democratic transition and consolidation: Southern Europe, Southern America and post-Communist Europe, Baltimore, John Hopkins University Press, 1996; COLOMER, Josep M., La transición a la democracia: el modelo español, Barcelona, Anagrama, 1998; ALEXANDER, Gerard, The sources of democratic consolidation, London, Cornell University Press, 2002; GUNTHER, Richard; MONTERO, José R., y BOTELLA, Joan, Democracy in modern Spain, New Haven-London, Yale University Press, 2004.

2 “...burocratización y racionalización de la Administración Pública que (...) aseguraba una mayor neutralidad política y creaba la base para que dentro del propio Estado se multiplicasen las posiciones de poder no directamente relacionadas con la adscripción a una u otra familia política del régimen”, en JULIÁ, Santos y MAINER, José C., El aprendizaje de la libertad. 1973-1986, Madrid, Alianza, 2000, pp. 26-27.
} 
de la cultura política, no resulta fácil distinguir el orden causal en el tiempo entre cultura e instituciones políticas, entre las causas y consecuencias.

En el extremo opuesto se han situado las teorías basadas en los actores políticos, las preferidas, por razones obvias, de los protagonistas reales o presuntos de la transición y de sus herederos personales o políticos ${ }^{3}$. Ponen el acento en la incertidumbre de la situación y la naturaleza contingente de las decisiones, por tanto, en la habilidad de los protagonistas, en el éxito de las élites políticas implicadas y sus estrategias de ingeniería política. En el caso español se trataría de los sectores reformistas del franquismo y de la trinidad formada por el rey, Adolfo Suárez y Torcuato Fernández Miranda, quienes no sólo habrían llevado la iniciativa sino incluso previsto con clarividencia todos los pasos jurídico-políticos del proceso, según las versiones más interesadas, mientras que las versiones más atendibles hacen hincapié en su pacto con las élites de la oposición antifranquista, ante la mutua constatación del equilibrio de fuerzas.

Sobre los estudios de transitología acecha siempre el riesgo de teleologismo, es decir, de juzgar el proceso por sus resultados cuando éstos son ya bien conocidos y en esto el caso español no es una excepción. Al final, como ha escrito Miguel A. Aguilar, parece que todo estuviera escrito en la pizarra de Suresnnes -como pretendía Alfonso Guerra- o en la de la Zarzuela - como reclamaba el sobrino de Fernández. Miranda en unas memorias de ultratumba de su pariente- o en la de Estoril por mano de Pedro Sáinz Rodríguez, según preferencia de Luis María Ansón ${ }^{4}$. En términos más académicos, los de Víctor Pérez Díaz, no obstante los procesos de transición política puedan ser reconstruidos ex post facto como una sucesión de decisiones críticas tomadas por las élites, conviene entender que aquellas decisiones son, con frecuencia, reacciones a procesos en marcha que las élites difícilmente pueden entender y menos aún controlar ${ }^{5}$. Alguien que lo vivió en primera persona, la ya fallecida Carmen Díez de Rivera, mano derecha de Suárez, recordaba cómo no existió un proceso fluido con la Constitución como meta, sino que fueron empujando los acontecimientos ${ }^{6}$.

No han faltado críticas a esta interpretación centrada en las élites, que suele consistir más bien en una descripción desde la historia política, por cuanto supervalora la función de dichas élites en detrimento de los factores sociales, culturales e institucionales sobre los que actúan y en detrimento de las presiones ascendentes de la sociedad, al menos de sus sectores más movilizados. Ya durante la transición algunos observadores constataron la distancia entre los intereses mayoritarios de la población y los dirigentes políticos, por supuesto del régimen pero también de la oposición de izquierda, que se vieron obligados a importantes modificaciones en sus proyectos, discursos y actitudes ante las demandas sociales de cambio profundo y en orden al mismo tiempo. Porque una cosa era la política-ficción, como la definió Pedro Altares desde las páginas de Cuadernos para el Diálogo, a la que se acostumbró la oposición durante los largos años del franquismo-por no hablar de la falsa retórica y cinismo político de éste- y otra muy distinta la

\footnotetext{
Así, por ejemplo, en FERNÁNDEZ MIRANDA, Pilar y Alfonso, Lo que el rey me ha pedido, Barcelona, Plaza y Janés, 1995. Un modelo basado en el protagonismo de las élites en O'DONELL, Guillermo, SCHMITTER, Philippe C. y WITHEHEAD, Laurence, Transitions from Authoritarian Rule, Baltimore-London, John Hopkins University Press, 1986 (trad. esp., Transiciones Desde un Gobierno Autoritario, Buenos Aires, Paidós, 1988-1989). Ver también HIGLEY, John y GUNTHER, Richard, Elites and democratic consolidation in Latin America and Southern Europe, Cambridge University Press, 2992; CAMPUZANO, Francisco, L'élite franquiste et la sortie de la dictature, París, L'Harmattan, 1997; ENCARNACIÓN, Omar G., The legacy of transitions: pact-making and democratic consolidation in Spain, Madrid, Juan March, 2003; HUSLER, Angelo, Du franquisme à la démocratie: effondement ou évolution d'un regime?, Lausanne, L'Àge du Homme, 2003, y PALOMARES, Cristina, Sobrevivir después de Franco. Evolución y triunfo del reformismo, 1964-1977, Madrid, Alianza, 2006.

AGUILAR, Miguel A., “'Hara kiri' para enterrar un régimen”, El País, especial El rey del cambio, 22-XI-2005.

PÉREZ DÍAZ, Víctor, La primacía de la sociedad civil, Madrid, Alianza, 1993, p. 22.

ROMERO, Ana, Historia de Carmen: memorias de Carmen Díez de Rivera, Barcelona, Planeta, 2002.
} 
política real, en la que se toman decisiones que tienen consecuencias. Porque nadie niega el protagonismo de personalidades como Suárez, menos aún la importancia del pacto y la negociación en la fase crítica de los años 1976-1978, sino el hecho de convertirlos en explicaciones suficientes de un proceso bastante más complejo.

Como ha señalado Pere Ysàs, la tesis de que la democracia actual no sería sino obra de los reformistas del franquismo es paralela a otra que afirma la debilidad de la oposición, olvidando por un lado la centralidad de la violencia represiva en la supervivencia del régimen, de manera que el silencio y la indiferencia de amplios sectores de la población no pueden confundirse con un apoyo a la dictadura, ni explicarse sin recurrir al miedo persistente que ésta logró inocular en el cuerpo social durante sus primeros años (y que administró hasta el final). Olvidando, por otro lado, que el disenso tuvo variadas expresiones, desde el rechazo pasivo hasta la oposición activa, estuvo presente de forma continuada en la sociedad española, en especial desde finales de los años cincuenta, y creció a partir de entonces hasta convertirse en un factor decisivo de la vida política ${ }^{7}$.

Hace ya veinte años José M. Maravall siguió el modelo general de transición elaborado por Rustow $^{8}$ para observar cómo las presiones reivindicativas desde abajo, es decir, los movimientos sociales, empujaron y configuraron la política reformista desde arriba, hasta hacer viable una estrategia de pactos entre las élites políticas. Todo ello en el marco de una situación ambigua o dual en la que sectores sociales movilizados conviven con otros desmovilizados o apáticos, fruto de casi cuarenta años de dictadura, o donde una elevada legitimación democrática coexiste con una baja militancia partidista o un reducido asociacionismo social ${ }^{9}$. Por su parte, Pérez Díaz ha tratado también de superar ese dilema poco iluminador entre los dos extremos del decisionismo y del determinismo considerando a los actores políticos menos como agentes que toman decisiones y más como agentes que siguen o rompen unas reglas, cuyas decisiones estratégicas están siempre constreñidas por condiciones previas aunque sean capaces de alterarlas.

Y esas condiciones no son otra cosa que las nuevas tradiciones sociales que algunos grupos fueron desplazando hacia el centro del sistema social a lo largo de la última década de la dictadura y ampliando en su impacto gracias a los medios de comunicación de masas, sobre todo tras la aprobación de la Ley de Prensa e Imprenta de 1966, con la creación de una esfera pública de discusión. De modo que, en palabras de Pérez Díaz, a mediados de los setenta, los estilos de vida de la sociedad civil eran, en gran medida, liberales y democráticos: es lo que ha llamado la emergencia de la sociedad civil, que preparó el camino de la transición mediante una variedad de mecanismos ${ }^{10}$. Entre ellos la elaboración de un lenguaje democrático que destaca el papel integrador de la política frente a la violencia, así como el surgimiento de tradiciones que influyen en los diseños

\footnotetext{
YSÀS, Pere, Disidencia y subversión. La lucha del régimen franquista por su supervivencia, 1960-1975, Barcelona, Crítica, 2004.

8 MARAVALL, José M., La política de la transición, Madrid, Taurus, 1984; RUSTOW, Dankwart A., “Transition to Democracy: Towards a Dynamic Model”, en Comparative Politics, 2 (1970), pp. 337-363, según el cual hay una fase preparatoria consistente en una lucha política prolongada y sin solución, protagonizada por un movimiento de masas, y en segundo lugar una fase de decisión en la cual una fracción decisiva de los dirigentes políticos aceptan un compromiso pluralista y democrático para salir del impasse y evitar un enfrentamiento civil (aquí un pequeño círculo de dirigentes, entre ellos muchos representantes de la fase preparatoria, desempeñan un protagonismo importante).

9 Sobre esas paradojas de la movilización social, ver MONTERO, José R.; GUNTHER, Richard y TORCAL, Mariano, Democracy in Spain: legitimacy, discontent and disaffection, Madrid, Juan March, 1997; McDONOUGH, Peter; BARNES, Samuel H. y LÓPEZ PINA, Antonio, The cultural dynamics of democratization in Spain, Ithaca, Cornell University Press, 1998; OÑATE RUBALCABA, Pablo, Consenso e ideología en la transición política española, Madrid CEP, 1998, o SASTRE GARCÍA, Cayo, Transición y desmovilización política en España (1975-1978), Universidad de Valladolid, 1997.

$10 \quad$ Ob. cit. pp. 52 y $56-58$.
} 
institucionales y las políticas públicas, que educan a las clases políticas, crean símbolos políticos, dan sentido a los actos y conforman los entendimientos (cognitivos), juicios (valorativos) y comportamientos (actuativos) básicos, a menudo tácitos, de la política democrática cuando las reglas de juego han sido interiorizadas. Quizás ese papel predominante de la sociedad civil no lo explica todo o no es causa suficiente para la transición, pero sí para su éxito y consolidación.

Dicho desarrollo de tradiciones democrático-liberales, de un lenguaje político y unos símbolos políticos edificantes incluye la reconstrucción de la memoria colectiva que ha llevado a la reconciliación y a un nuevo entendimiento de la historia de España, sobre todo mediante la reinterpretación de la guerra civil como una tragedia inevitable ${ }^{11}$. Todo ello dentro de un proceso que contempla tanto la emergencia como la invención, es decir, las construcciones sociales no deliberadas junto con las conscientes, o más bien la combinación de ambas. Según Pérez Díaz, el éxito de las élites políticas habría sido el de aprender con rapidez de esas meta-reglas de la vida social, económica y cultural, el de adecuar a ellas el nuevo sistema institucional: de ahí el acierto del llamamiento televisado del presidente Suárez en septiembre de 1976 para hacer normal en la vida política lo que ya era normal en la calle (eso sí, con un claro elemento moderador o limitador, según se mire, que fue el ejército) ${ }^{12}$. Como ha escrito Santos Juliá, La transición no era nueva, sino vieja de treinta años, en su exigencia básica: fin del discurso de la guerra, reconciliación, amnistía y renuncia de la revancha. La transición fue nueva en sus agentes ${ }^{13}$.

La sociedad civil sólo puede existir, asimismo, gracias al desarrollo instituciones de autocoordinación dentro de la sociedad, en particular asociaciones voluntarias y mercados, de una esfera de debate público y de áreas institucionales reservadas o privadas, libres de la intervención del gobierno. Es aquí donde el concepto de espacios públicos liberados, definidos por Habermas como redes de comunicación de opiniones públicas autónomas e independientes del poder, se ha mostrado más útil en los últimos estudios sobre el segundo franquismo ${ }^{14}$. Hasta alguien tan poco sospechoso como Rodolfo Martín Villa, por entonces joven consejero nacional y luego apasionado defensor del protagonismo de los reformistas del franquismo en una transición ordenada, reconoce que el régimen había renunciado a mantener su control sobre extensas áreas de la vida social española y ésta se había organizado un poco a su aire, al margen de la situación ${ }^{15}$. En esa lenta conquista de esos espacios libres -y Cuadernos para el Diálogo fue uno de ellos- se generó el cambio cultural que acompañó a la movilización social y precedió al cambio político, aunque conforme se acercaba el final de la dictadura esa lucha de la oposición por parcelas de libertad se fuera convirtiendo cada vez más en otra por parcelas de poder ${ }^{16}$.

Quizás para muchos opositores al franquismo dentro de España o en el exilio tales conclusiones no eran otra cosa que redescubrir el Mediterráneo, conscientes como fueron desde el primer momento de que no cabía otra vía, ante la impotencia de la derrota y la brutal represión, que

11 MUÑOZ SORO, Javier, "Entre la memoria y la reconciliación. El recuerdo de la República y la guerra en la generación de 1968", en Historia del Presente, 2 (2003), pp. 83-100. Ver también AGUILAR, Paloma, Justicia, política y memoria: los legados del franquismo en la transición española, Madrid, Juan March, 2001.

12 Ob. cit. p. 19.

13 JULIÁ, Santos y MAINER, José C., El aprendizaje..., cit., p. 45.

14 HABERMAS, Jürgen, Droit et démocratie. Entre faits et normes, Paris, Gallimard, 1997; EVANS Sara M. y BOYTE, Harry C., Free Spaces: The Sources of Democratic Change in America, Nueva York, Harper and Row, 1986; SEVILLANO CALERO, Francisco, "Cultura y disidencia en el franquismo: aspectos historiográficos", en Pasado y Memoria, 2 (2003), pp. 307-316.

15 MARTÍN VILLA, Rodolfo, Al servicio del Estado, Barcelona, Planeta, 1984, pp. 41-42.

16 DORADO, Roberto y VARELA, Ignacio, "Estrategias políticas durante la Transición”, en TEZANOS, José F.; COTARELO, Ramón y DE BLAS, Andrés, La Transición..., cit., pp. 251-274. 
la reconstrucción de lo que Manuel Vázquez Montalbán llamó razón democrática ${ }^{17}$. Desde los campos de internamiento franceses, como ha recordado Dreyfus-Armand ${ }^{18}$, la lucha contra el franquismo se emprendió en nombre de la defensa de la cultura y esa tarea de educación política, de toma de conciencia ideológica, de recuperación de la memoria histórica puso ya las bases del renacer de la sociedad civil. En los años sesenta eso no había cambiado, al revés, los valores culturales se multiplicaron exponencialmente pese a que la política fue recuperando posiciones en la sociedad y pese a que no faltaron los grupos que depositaron sus esperanzas en el voluntarismo revolucionario y la acción violenta.

Frente al mito del asalto al Palacio de Invierno o, en su versión española, al Palacio del Pardo -pues dentro del oportunismo revolucionario de la izquierda nunca dejó de haber sitio para los atentados contra Franco, los golpes de Estado o las insurrecciones populares- se impuso en el antifranquismo una cultura política gradualista de guerra de posiciones desarrollada también al nivel de las conciencias. La había teorizado Gramsci desde la cárcel: la cultura era un campo privilegiado de la confrontación ideológica y para llevar a cabo la revolución era necesario acumular saber, un saber crítico orientado hacia el cambio y capaz de oponerse al saber del antagonista ${ }^{19}$. Era precisamente allí donde resultaba insustituible la función de revistas como Cuadernos para el Diálogo, Triunfo, Destino o, fuera de España, Cuadernos de Ruedo Ibérico.

Ese combate de la cultura tuvo un derrotado claro: el régimen franquista. Éste renunció desde muy pronto a integrar amplios sectores sociales en un proyecto cultural nacional -el totalitario de los falangistas de la revista Escorial en los cuarenta o el de los comprensivos en los cincuenta- y más aún en los años sesenta, cuando orientó su búsqueda de nuevas fuentes de legitimación hacia el desarrollismo tecnocrático y no hacia la hegemonía cultural y educativa ${ }^{20}$. Lo reconocieron explícitamente personalidades el régimen como el ministro e ideólogo del crepúsculo de las ideologías González de la Mora -perdimos una batalla de pensamiento- o el periodista Emilio Romero, al admitir que revistas como Cuadernos para el Diálogo o Triunfo carecían de equivalentes en el campo del régimen ${ }^{21}$. Lo demostraron implícitamente los reiterados fracasos en el intento de pasar a la ofensiva en el campo de la información y la contrainformación: campañas secretas como las del ministro Sánchez Bella, destinadas a disminuir el impacto de publicaciones tipo Ruedo Ibérico mediante la edición en el extranjero de revistas y otras publicaciones sobre temas de política española que estarían formalmente prohibidas en España y utilizarían la firma de personas con filiación conocida como opuesta al Régimen ${ }^{22}$.

Precisamente la Ley de Prensa e Imprenta de 1966 nos permite analizar una cuestión tan relevante en el los procesos de cambio social como es determinar su origen y fuerza motriz, pues afirmar que todo cambio social es posible gracias a una apertura en el sistema político no pasa de ser una tautología. Lo que importa es saber hasta qué punto tal apertura, en el caso del

17 VÁZQUEZ MONTALBÁN, Manuel, “Liberación de añoranzas”, en ALTED, Alicia y AUBERT, Paul (eds.), Triunfo en su época, Madrid, Casa de Velázquez-Ediciones Pléyades, 1995, pp. 171-179.

18 DREYFUS-ARMAND, Geneviève, El exilio de los republicanos españoles en Francia. De la guerra civil a la muerte de Franco, Barcelona, Crítica, 2000, p. 89.

19 GRAMSCI, Antonio, Cartas desde la cárcel, Madrid, Edicusa, 1975.

20 Ver JULIÁ, Santos, Historias de las dos Españas, Madrid, Taurus, 2004; GRACIA, Jordi, La resistencia silenciosa. Fascismo y cultura en España, Barcelona, Anagrama, 2004; MORENTE, Francisco, Dionisio Ridruejo. Del fascismo al antifranquismo, Madrid, Síntesis, 2006; MOLINERO, Carme, La captación de las masas. Política social y propaganda en el régimen franquista, Madrid, Cátedra, 2005.

21 CHULIA, Elisa, El poder y la palabra. El régimen de Franco ante la prensa y el periodismo, Madrid, Biblioteca Nueva, 2001, p. 218.

22 Asunto: revista sobre temas de política española, s/f (1970-1971); Pamplona, Archivo Histórico de la Universidad de Navarra, Fondo Sánchez Bella. 
franquismo más fáctica que institucional, responde a una voluntad política gubernamental en ese sentido o a una presión social desde abajo -e internacional desde fuera- que hace inevitable la adaptación para la supervivencia del sistema. Y como está fuera de discusión que la Ley de Prensa de 1966 tuvo un efecto positivo en el proceso de emergencia de la sociedad civil, haciendo posible el surgimiento de una esfera pública de debate, la conclusión más habitual es interpretar su sentido como una apertura del régimen hacia formas de participación más plurales, en la línea definida por Juan J. Linz de los autoritarismos de pluralismo limitado ${ }^{23}$.

A favor de esa tesis puede argüirse que, con la promulgación de la ley, el ministro Fraga Iribarne pretendía al mismo tiempo satisfacer las demandas de una mayor libertad de información procedentes de los sectores católicos -recogidas en el Decreto sobre los medios de comunicación social del Concilio Vaticano II- y realizar su propio proyecto neofalangista para revitalizar el régimen y relegitimarlo dentro del Movimiento mediante el desarrollo de una opinión pública limitada. Hacer lo que desde hacía tiempo pedían sus periodistas: dejarles trabajar impulsando el consenso en torno al régimen, encorsetado dentro del mecanismo excepcional, lento y farragoso de la censura previa, eso sí, dentro de los límites marcados por la aceptación de los principios del 18 de julio ${ }^{24}$. Además, ese paso decisivo hacia la liberalización del régimen no sería ni mucho menos aislado, sino coherente con otros encaminados desde finales de los años cincuenta a la modernización administrativa y la institucionalización política, con evidentes implicaciones sociales.

Sólo que la ley llegaba demasiado tarde, cuando gran parte de los universitarios e intelectuales se habían alejado definitivamente del franquismo y el mundo católico se encontraba profundamente dividido, y al final lo único que conseguirá es hacer aún más visibles las contradicciones del sistema, atrapado entre sus exigencias de control social y el proceso de modernización de la sociedad impulsado por él mismo. La nueva Ley de Prensa fue, desde la perspectiva del régimen -del ejército, de la alta jerarquía eclesiástica, de los falangistas, de los opusdeístas - sólo un rotundo fracaso y un contraproducente error. Lo acabaría reconociendo hasta el propio ministro de Información y Turismo, Sánchez Bella: no se podía pretender sustituir unos criterios políticos -censura previa- por otros jurídicos, aun fuertemente limitados por la discrecionalidad administrativa -ley de prensa-, cuando los objetivos perseguidos seguían siendo eminentemente políticos. Los ministros tecnócratas acabaron enfrentándose con los falangistas por el uso de la prensa (Caso Matesa) y en el Ministerio de Información y Turismo, una cartera caliente que ya nadie quería, las cabezas rodaron una detrás de otra.

Desde el punto de vista de la sociedad, sin embargo, la Ley de Prensa de 1966 fue una espita más por donde dar salida a sus energías, a sus ansias de consumo cultural y su lucha por las libertades políticas. Porque a esa dimensión interior o nacional del cambio se superponía, además, otra global. No hay que olvidar que los años sesenta ven en España la intensificación de procesos iniciados antes de la guerra pero interrumpidos por ésta, como eran la internacionalización de las formas de cultura y la progresiva anulación de las diferencias entre clases sociales ante la oferta cultural, a lo cual venía a sumarse ahora su creciente comercialización en los mercados de consumo neocapitalistas. Nunca antes, ni quizás después, en España ha significado tanto el término 'cultura' como en los días de la transición, según José Carlos Mainer, quien también ha escrito:

23 LINZ, Juan J., "Opposition in and under an autoritarian Regime: the case of Spain", en DAHL, Robert (ed.), Regimes and Oppositions, New Haven, Yale University Press, 1973.

24 Discurso del ministro Fraga en la presentación de la ley ante las Cortes, en FERNÁNDEZ AREAL, Manuel, La libertad de prensa en España (1938-71), Madrid, Edicusa, 1968, p. 62 y ss. 
Era obvio que sus cortapisas y sus ausencias, su añoranza y su culto, hubieron de ser una parte sustancial de la conciencia antifranquista y, en cierto modo, el primer umbral de acceso a la mentalidad opositora; por eso, ni siquiera los más reacios a admitir los errores del régimen acudían a defenderlo cuando se trataba de sus pecados o sus insuficiencias en materia de libertades culturales en los últimos años ${ }^{25}$.

Por eso también revistas como Cuadernos para el Diálogo o Triunfo llegaron a convertirse en referencias dominantes -como luego El País durante la transición ${ }^{26}$ - para amplios sectores de la población, en señas de identidad, para propios y extraños, del cambio. Y por eso sus páginas, como ocurrió con la polémica cultural de 1970, o incluso su propia desaparición al llegar la democracia por la que tanto habían luchado, anunciaron con antelación otras crisis inminentes: de la cultura del progresismo, de la unidad política del antifranquismo y de la intensa movilización cívico-social en los últimos años de la dictadura y los primeros de la transición.

\section{CUADERNOS PARA EL DIÁLOGO Y EDICUSA, UN LUGAR DE SOCIABILIDAD INTELECTUAL}

En ese proceso de cambio sociocultural y aprendizaje del lenguaje de la democracia las revistas toleradas, las editoriales en pleno boom del libro y tantas otras iniciativas culturales propiciaron el encuentro entre intelectuales de diversas generaciones. En el caso de Cuadernos para el Diálogo, intelectuales que procedían del falangismo y el catolicismo de la posguerra (Joaquín Ruiz-Giménez, Aranguren, Laín Entralgo y muchos otros que se autoidentificaron con una supuesta generación del 36) con sus jóvenes alumnos o colaboradores de la universidad, los que solemos incluir en las bien o mal llamadas generaciones de 1956 y 1968. No cabe duda del papel relevante que correspondió a esos jóvenes estudiantes e intelectuales universitarios que años después pasarían a ocupar una parte muy considerable del poder político, cultural y académico de la democracia española. En esas empresas culturales tuvieron unos medios privilegiados de acción, pronto utilizados en la lucha contra el franquismo, al principio dentro de una convivencia común que entraría en crisis desde 1968 para dar paso en los años sucesivos a una extrema fragmentación política y a un mayor radicalismo ideológico. La inminente muerte de Franco llevaría a muchos de ellos otra vez hacia la unidad, bien en plataformas unitarias de la oposición, bien en la confluencia dentro de los partidos obreros históricos, y hacia el pragmatismo político, del que darían buena muestra al alcanzar el poder ya en democracia.

Esos estudiantes y licenciados universitarios habían nacido durante los años de la guerra e inmediata posguerra -la mayoría entre 1935 y 1945 - y, por tanto, tenían una edad entre veinte y treinta años a mediados de la década de los sesenta. Pese a su juventud -hoy los jóvenes suelen iniciar más tarde sus carreras académicas, profesionales o políticas-por entonces publicaron sus primeros libros y artículos en revistas como Cuadernos para el Diálogo o Triunfo, y ejercían ya algún tipo de actividad intelectual bien como profesores adjuntos o no numerarios (PNN) en la universidad, bien como periodistas, escritores o editores. Podían compaginar esa actividad con otros trabajos en el sector público (funcionarios medios, jueces, fiscales, inspectores o diplomáticos) o en el sector privado (profesionales liberales, abogados, médicos, arquitectos o ingenieros), aunque cada vez se reproducían menos los tipos otrora abundantes del novelista-médico, editorialista-funcionario, poeta-ingeniero, filósofo-corrector de estilo u otros

25 JULIÁ, Santos y MAINER, José C., El aprendizaje..., cit., p. 147.

26 IMBERT, Gèrard y VIDAL BENEYTO, José, El País o la referencia dominante, Barcelona, Mitre, 1986. 
semejantes ${ }^{27}$. Ahora había más posibilidades en el mercado de trabajo para desarrollar su ocupación a tiempo completo en editoriales, revistas, periódicos, seminarios y otros centros de producción cultural, si bien la mayoría acabarían vinculándose a la universidad. Fuera de ésta serán cada vez más raras las carreras intelectuales (como fueron, por ejemplo, las de Dionisio Ridruejo o Ignacio Fernández de Castro).

En coherencia con la importancia que antes he señalado de la mirada retrospectiva hacia el inmediato -y traumático- pasado en la construcción de un proyecto cultural y político basado en nuevos valores morales, esos jóvenes intelectuales iniciaron sus carreras académicas con investigaciones y tesis sobre el regeneracionismo, el krausismo y la Institución Libre de Enseñanza, sobre Fernando Garrido, Fernando de los Ríos, Adolfo Posada, Manuel Sales i Ferré, Jiménez de Asúa, Julián Besteiro o Rafael Altamira, sobre la Segunda República o la Guerra Civil. Empezaron a conocer -porque tenían más posibilidades, pero sobre todo más interés y curiosidad- la obra cultural y científica del exilio, de gentes como Américo Castro, Sánchez Albornoz, Salvador de Madariaga, José Gaos, García Bacca, Eduardo Nicol, María Zambrano o Severo Ochoa, por no hablar de la literatura y las artes plásticas. Unas opciones académicas e intelectuales guiadas por el evidente deseo de buscar referentes de concordia, de pacificación, descartando otros asociados en la conciencia colectiva a los excesos de las militancias partidistas, los dogmatismos ideológicos y las violencias políticas que habrían conducido a la guerra fratricida.

Una mirada que se extendía tanto en el tiempo como en el espacio, pues buscaba nuevos horizontes fuera, sobre todo en Europa, de manera que Maritain, Mounier, Bobbio, Gramsci, Marcuse, Althusser, Garaudy, Lukács o Poulantzas también se convirtieron en referentes intelectuales de sus primeros trabajos. No dejaba de ser sorprendente, como lo fue para Francisco Ayala en 1965, ver a la juventud española sintonizada [...] nadie sabe mediante qué mecanismo generacional, con la juventud de los demás países europeos, tras la campana de cristal donde pretendía encerrarla el régimen franquista ${ }^{28}$. El anexo 2, con los títulos principales publicados por la editorial Edicusa (Editorial Cuadernos para el Diálogo SA) durante la última década de la dictadura, no es otra cosa que una muestra, limitada pero creo que suficientemente significativa, de la relevancia que cobró esta operación cultural retrospectiva y prospectiva.

Edicusa comenzó su despegue como empresa editorial en 1966, con la publicación de algunos de los libros más vendidos de toda su historia, como Moral y sociedad, de Aranguren, y Estado de Derecho y sociedad democrática, de Elías Díaz, a los que siguieron otros títulos de éxito: Estructura y problemas del campo español (1967), de Juan Anlló; el texto bilingüe de La pell de brau (1968), de Salvador Espriu; Historia y realidad del poder (1967 y 1970), de Tuñón de Lara; Ideologías y clases en la España contemporánea (1969), de Antoni Jutglar, o la obra en prosa de Machado (1970-1976). Estos títulos serían incorporados a la colección básica de la editorial, Divulgación Universitaria, que se convirtió en una referencia básica en la renovación de mentalidades en palabras de José Carlos Mainer ${ }^{29}$. Se crearon otras colecciones que tuvieron menos continuidad, como Cuestiones Españolas, Religión y Mundo, Cuadernos para el Diálogo, Esta Hora y Teatro, cuya aportación a la cultura teatral española también ha sido unánimemente reconocida.

Entre 1966 y 1968 Divulgación Universitaria vendió 96.595 libros por un valor de 4.324.000 pesetas. Sin embargo, el estado de excepción de 1969, al hacer casi imposible en la práctica la actividad editora durante varios meses, llevó a Edicusa a una situación económica

27 DE MIGUEL, Amando, "Intelectuales en España”, en Diario de Barcelona, 14-X-1972), cit. en OLTRA; Benjamín, Pensar en Madrid. Análisis sociológico de los intelectuales políticos en la España franquista, Barcelona, Euros, 1976, p. 147.

28 AYALA, Francisco, España, a la fecha (1965), cit. en GRACIA Jordi, La resistencia ..., cit., p. 330.

29 JULIÁ, Santos y MAINER, José C., El prendizaje..., cit., p. 209. 
crítica, con pérdidas superiores a los dos millones de pesetas, de la cual sólo se recuperaría lentamente ${ }^{30}$. Si ese año sólo fueron vendidos 30.535 ejemplares de Divulgación Universitaria, en 1971 fueron 100.451, saliendo por primera vez de números rojos y obteniendo beneficios, que ascendieron a 501.600 pesetas en 1972. Aquel mismo año Edicusa creó Distribuciones de Enlace junto a las editoriales catalanas Fontanella, Barral, Lumen, Estela (luego Laia), Tusquets, Anagrama y Edicions 62, al mismo tiempo potenciaba su expansión por América Latina ${ }^{31}$. Entre 1966 y 1972 la editorial produjo 790.100 volúmenes, de los cuales vendió 575.769, el $65,2 \%$, por un total neto de 27.017.100 pesetas. En septiembre de 1973 había treinta trabajadores de plantilla, entre ellos Pedro Altares, Rafael Martínez Alés, Vicente Verdú y Víctor Martínez Conde.

Por otra parte, en enero de 1973 salió el primer número de Sistema. Revista de Ciencias Sociales, publicada por el Instituto de Técnicas Sociales (ITS), creado a su vez en 1970 utilizando la cobertura legal de la Fundación Fondo Social Universitario que presidía RuizGiménez. Pronto se convirtió en el primer órgano de un matizado socialismo académico, que reunió a la vanguardia de la joven sociología crítica española bajo la dirección de Elías Díaz y con José F. Tezanos como secretario. La idea era que la revista publicara trabajos que por su extensión y características de mayor densidad teórica y científica no encajaban, por ejemplo, en Cuadernos para el Diálogo, en tanto que el ITS apoyaba la realización de tesis doctorales y los primeros estudios de las nuevas promociones universitarias, publicados en colaboración con Edicusa. Como resultado aparecieron durante esos años en la colección ITS de Edicusa un buen número de libros referidos a problemas y circunstancias de la situación española en el ámbito de la ciencia política, la economía, la sociología y la historia del pensamiento ${ }^{32}$.

\section{CUADERNOS PARA EL DIÁLOGO Y LA COLECCIÓN LOS SUPLEMENTOS}

Respecto a la prensa diaria, dominada por un monopolio estatal -la Prensa del Movimiento- o el control de algunas familias políticas y privadas -los católicos Ya o Madrid, los monárquicos $A B C$ o La Vanguardia- las revistas como Cuadernos para el Diálogo, Triunfo, Destino, Índice y otras muchas de difusión regional requerían una inversión mucho menor. Paradójicamente esa debilidad acabó por convertirse en su mayor fortaleza ante la censura y demás instrumentos de control gubernamental, y les permitió llenar no sólo un vacío informativo, el dejado por la sumisión de los grandes diarios, sino incluso político, convertidas en lo que pronto se llamaron parlamentos de papel a falta de otros verdaderamente democrá$\operatorname{ticos}^{33}$. En palabras de Félix Santos, director de Cuadernos para el Diálogo, su trabajo consistía en desintoxicar, desmitificar, informar, formar, dialogar a diversos niveles, ser cauce

30 Informe general sobre Edicusa, pp. 80-103; Archivo Rafael Martínez Alés, Madrid.

31 Los depósitos de Distribuciones de Enlace en Barcelona resultaron totalmente destruidos por un atentado de la extrema derecha en julio de 1974.

32 DÍAZ, Elías, "Breves notas para la prehistoria y la intrahistoria de Sistema", en Sistema, 100 (enero 1991), pp. 5-15.

33 Si bien la expresión se utilizaba mucho antes, en las democracias anglosajonas, para referirse a la prensa liberal como cuarto poder, también la historiografía ha recurrido a menudo al término, de indudable eficacia expresiva para el caso español: RENAUDET, Isabelle, Un Parlement de papier. La presse d'opposition au franquisme durant la dernière décennie de la dictature et la transition démocratique, Madrid, Bibliothèque de la Casa de Velázquez, 22 (2003), o MONTABES PEREIRA, Juan, "Los parlamentos de papel en el caso español", en FILGUIERA, Carlos y NOHLEN, Dieter (comps.), Prensa y transición democrática: experiencias recientes en Europa y América Latina, Madrid, Iberoamericana, 1994, pp. 42-67. 
de expresión de pluralismos ideológicos y políticos y demás tareas subsidiarias hasta del más elemental carácter informativo ${ }^{34}$.

Entre su fundación en 1963 y su cambio de periodicidad en 1976 -cuando no sólo pasó de ser mensual a semanal, sino también de ser un instrumento de acción política a una verdadera empresa periodística- la historia de Cuadernos para el Diálogo conoció dos procesos fundamentales y en cierta medida paradójicos. Por un lado, la revista aumentó su difusión y dio un gran salto adelante en su discurso de oposición al régimen, hasta el punto de llegar a ser considerada como una plataforma informal del antifranquismo. Por otro lado, si bien eso llevó como era lógico a una consolidación del proyecto político que estaba en su origen, culminado con la entrada de Ruiz-Giménez en Izquierda Demócrata Cristiana (IDC) en octubre de 1969, en realidad los resultados fueron bastante diferentes respecto a las expectativas iniciales. Porque, precisamente durante esos años, gran parte de los miembros del consejo de redacción y colaboradores habituales evolucionaron hacia la izquierda marxista, renunciaron a la democracia cristiana como vía para alcanzar sus objetivos políticos e incluso abandonaron la práctica religiosa y/o la fe, que en todo caso dejó de ser entendida como el impulso básico de su compromiso político. Eso se tradujo, ya en la década de los setenta, en nuevas militancias de partido y a la larga tuvo consecuencias importantes en la transición, sobre todo haciendo imposible la alternativa de una democracia cristiana de izquierda ${ }^{35}$.

Pero creo que el legado más importante de Cuadernos para el Diálogo, y lo que más nos interesa aquí, no fue tanto su trayectoria política con ser ésta relevante para el futuro de la democracia, sino su aportación a la emergencia de una sociedad civil, la reconstrucción de la razón democrática, la reconciliación, la recuperación de la memoria perdida y la elaboración del nuevo lenguaje de la democracia. Y en esa obra eminentemente cultural la revista -más expuesta a la censura por su mayor visibilidad y sobre todo más centrada en las cuestiones jurídico-políticas, la deslegitimación del régimen, la denuncia de sus contradicciones y abusos o la defensa de las libertades y los derechos humanos- se sirvió de otros instrumentos, en particular su editorial, Edicusa, sus números extraordinarios y la colección Los Suplementos.

La idea de Los Suplementos surgió ante la imposibilidad de publicar un semanario, a causa de las trabas impuestas por el Ministerio de Información y Turismo para la inscripción de Cuadernos para el Diálogo en el Registro de Empresas Periodísticas (REP), una espada de Damocles que pendía sobre los diarios y revistas críticas. Como se sabía que uno de los criterios de la censura era la mayor o menor difusión de las publicaciones, el consejero delegado de Edicusa, José María Riaza, presentó la solicitud de autorización a la Dirección General de Prensa destacando que su contenido estará constituido por ensayos densos, estudios, informes, documentos, reseñas bibliográficas y de revistas y otro material análogo que no tiene cabida en la actual revista y que sólo interesará a un núcleo de lectores bastante más restringido, dada su naturaleza y características $^{36}$. La Dirección General de Prensa dio esta vez su autorización, eso sí, supeditada a que no se produjera modificación o incumplimiento de las concesiones del permiso de edición concedido bajo amenaza de cierre ${ }^{37}$.

El primer número de Los Suplementos apareció en 1968 y recogía las actas de la Semana Internacional de Teología organizada por la Universidad de Deusto, con el título Mesa redonda

34 “Juicio crítico a Cuadernos para el Diálogo”, en Cuadernos para el Diálogo, 100 (enero 1972), pp. 29-30.

35 Ver MUÑOZ SORO, Javier, Cuadernos para el Diálogo (1963-1976). Una historia cultural del segundo franquismo, Madrid, Marcial Pons, 2006.

36 Escrito de José M. Riaza a la Dirección General de Prensa, 17-I-1968; expediente 1127, Archivo General de la Administración (AGA), Sección Presidencia del Gobierno (SPG), caja 136.

37 DIRECCIÓN GENERAL DE PRENSA, respuesta al escrito de José M. Riaza; expediente 1127, AGA-SPG, caja 136. 
sobre el ateísmo. La colección tuvo muy buen acogida y ya el primer año vendió 35.321 ejemplares. Los títulos, aparte de su calidad intrínseca, son una muestra de una sociedad en cambio en aspectos que iban desde la educación a la ecología (ver anexo 1). Entre los que alcanzaron mayor resonancia pueden citarse Los derechos humanos, de González Casanova; El bachillerato, ¿para qué?, de José F. Tezanos; La ciudad, de Antonio Fernández Alba; Vietnam, de Eduardo Haro Tecglen, Roberto Mesa y Mariano Aguilar Navarro; los números colectivos España, realidad y política, y Quién es quién en las Cortes (1969), o El apasionante mundo del tebeo (1968), de Antonio Lara. Como muestra este último título, Los Suplementos abordaban temas más cercanos a la cambiante realidad social y más abiertos a sus múltiples manifestaciones que la revista de referencia, Cuadernos, caracterizada por un lenguaje jurídico-político constreñido dentro de los márgenes mucho más estrechos del activismo antifranquista. Algunos llegaron a convertirse en verdaderos hitos en la cultura progresista, como ocurrió para el feminismo con el suplemento Mujer y aceleración histórica (1972).

Como bien puede imaginarse, todo ello acarreó a la editorial problemas con las autoridades, que amenazaron con utilizar contra Cuadernos para el Diálogo y Edicusa los mismos mecanismos que llevaron al cierre de la revista Aún, el diario Madrid o las editoriales Estela y ZYX, en especial la no inscripción en el REP. Por su parte la censura hizo siempre de la edición de libros una aventura arriesgada y sometida al vaivén de unos criterios bastante arbitrarios que podían llevar, en el mejor de los casos, a la supresión de unos párrafos y, en el peor, a la destrucción de ediciones enteras o incluso al procesamiento de sus autores por el Tribunal de Orden Público (TOP).

\section{EL ESTADO CONTRA EDICUSA: LA CENSURA DE LIBROS}

Los siguientes casos de censura ilustran, espero que de forma expresiva, sobre tres diferentes frentes que el régimen franquista tenía abiertos ante otras tantas vías de avance del cambio sociocultural: la denuncia jurídico-política de una dictadura que intentaba presentarse ante el mundo como un Estado de Derecho; la memoria histórica en asuntos tan sensibles para el régimen como las relaciones con Iglesia, la represión o la obra de los intelectuales republicanos; y la cultura progresista simbolizada por el movimiento juvenil de mayo del 68 . Y espero que de forma igualmente expresiva ayuden a cuestionar la tesis que interpreta la Ley de Prensa e Imprenta de 1966, la institucionalización de la dictadura con la Ley Orgánica del Estado de ese mismo año y la obra de los presuntos reformistas del franquismo -Fraga Iribarne y Carlos Robles Piquer, futuro ministro de la monarquía, a la cabeza - como el impulso motor del cambio.

Así, uno de los primeros títulos publicados por Edicusa, Estado de Derecho y sociedad democrática (1966) de Elías Díaz, fue inicialmente secuestrado por la extrema gravedad de sus ataques a la verdad y a las Leyes Fundamentales del Estado y la consiguiente repercusión que esta obra puede tener en contra del mantenimiento del orden público interior al afectar al prestigio de las instituciones, que servirá de base 'doctrinal' a más de un joven detractor del régimen, en sus fáciles discursos de tipo subversivo. De manera que se procedió al secuestro de la edición, incoado un expediente administrativo y su autor denunciado al TOP, y eso aun admitiendo que era un estudio serio y documentado, donde jamás se cita al régimen político español, y que la misma evolución del pensamiento político del régimen en los 30 años de su existencia hace muy delicado el dictaminar sobre esta obra de la editorial 'Cuadernos para el Diálogo', de significación política bien conocida ${ }^{38}$. Al final debieron de prevalecer estas últimas

38 Expediente de censura 6996/66, AGA, Sección Cultura (SC), caja 17.648. 
razones para que el TOP permitiera su publicación, algo que por supuesto no gustó en el Ministerio de Educación y Turismo, que en adelante trataría de evitar esta desmesurada atención de la censura pues sólo conseguía suscitar el interés de la prensa nacional e internacional.

En enero de 1968 fueron secuestrados los pliegos, dispuestos para encuadernación, del libro de Antonio Menchaca La URSS, hoy. Si bien la emisora comunista Radio España Independiente, más conocida como La Pirenaica, denunciaba como causa del secuestro que el señor Fraga Iribarne considera peligroso que se digan las verdades sobre la URSS porque ello podría servir para incrementar peligrosamente el número de los comunistas españoles, que ya es muy elevado, en realidad el libro ofrecía un retrato relativamente crítico de la URSS, no tanto de los logros alcanzados por el régimen soviético como del terror stalinista y la depuración de los intelectuales ${ }^{39}$. En el Ministerio no gustaron ciertas comparaciones con el régimen franquista, algunas referencias a la División Azul y a los españoles exiliados y, muy en particular, el prólogo, donde impertinentemente se hace una revisión crítica de la actividad de política internacional de nuestro Régimen en la etapa de la II Guerra mundial y posterior, en párrafos como el reproducido a continuación:

Como el lector sabe perfectamente, España fue proyectada en 1938 hacia el pasado como en esos espacios de la televisión que se llaman 'El túnel del tiempo', con tal violencia, que los españoles en bloque fuimos a parar al siglo XVI O XVII. La 'escorialitis" o mal de piedra en la arquitectura; el culteranismo barroco en el arte poético de fabricar sonetos; el esteticismo patriarcal en la filosofía; el precapitalismo en la economía; el gremialismo en la organización social; la contrarreforma y la censura en el pensamiento; el ritualismo en la religión; la monarquía absoluta en formas políticas, y las cortes medievales con sus ricos-homes, sus eclesiásticos, sus notables y artesanos. El impulso ideológico, el culatazo, consistía en el 'antimodernismo', que se descomponía en tres facetas: 'antiliberalismo', 'antidemocracia', 'anticomunismo'. En nuestras relaciones internacionales este cuadro se traduce en una actitud de 'no beligerancia' en el conflicto armado de escala mundial y justamente 'a favor' del que iba a perderlo. Pero, naturalmente, una cosa es condenar al siglo XX en nombre del XVII y otra tener que vivir en el XX, por lo cual el regreso del pasado al presente, el reingreso en la comunidad actual de pueblos obligaba a suprimir algún 'anti' de aquella trinidad totalitaria, y es así como poco a poco quedó en pie sólo el 'anticomunismo'. Los otros dos 'anti' fueron evaporándose cuando, al salir del 'Túnel del tiempo' y caer en el siglo XX, nos encontramos girando como satélites solitarios de uno de los vencedores contra el otro ${ }^{40}$.

Pero el mayor conflicto se planteó con La Iglesia en España, ayer y mañana del sacerdote Víctor Manuel Arbeloa, una encuesta sobre la actuación de la Iglesia durante la Segunda República realizada entre más de un centenar de protagonistas de ese periodo, desde destacados franquistas hasta exiliados republicanos y católicos que, si bien habían apoyado la sublevación en 1936, no enjuiciaban mucho mejor que los anteriores la alianza entre el régimen franquista y la jerarquía eclesiástica. Por ejemplo, el católico José Bergamín hablaba de la actitud negativa de la Iglesia en la sangrienta Cruzada de 1936, cuya responsabilidad le corresponde por entero; el republicano Manuel Torres Campaña de un clero que recuerda la guerra civil y siente la conciencia perturbada por su papel en ella y en la represión, y otro exiliado, el anarquista Francisco Gómez Peláez, de la Iglesia, asociada primero a las fuerzas de la reacción y auxiliar después en la implacable represión ejercida por los vencedores.

No menos críticas eran las declaraciones de algunos católicos catalanes y vascos: Ramon d'Abadal reconocía que la Iglesia no debió de tomar partido y mucho menos enrolarse en una

39 Radio España Independiente, emisión del 12-I-1968.

40 Ésta y las siguientes citas en el expediente de censura 3967/68, AGA-SC, caja 18.942. 
campaña contra el régimen legal, llegando incluso a bendecir las armas de la subversión en una contienda entre españoles, y menos aún a no oponerse con firmeza a las crueles persecuciones posteriores a la guerra civil; Coll i Alentorn, de Unió Democràtica de Catalunya, se refería a la revuelta militar fascista, mientras que Maurici Serrahima oponía el ejemplo de Vidal i Barraquer al doloroso caso del cardenal Gomá. El presidente del gobierno vasco en el exilio Manuel de Irujo calificaba, con gran escándalo de un censor, de ciegamente irresponsable y vengativa la legislación franquista anulatoria de los matrimonios celebrados durante la guerra en zona roja con todos los requisitos canónicos entonces y en tales circunstancias exigibles ${ }^{41}$.

Tras varias lecturas, una consulta con el asesor religioso del Ministerio, la exclusión de algunos nombres y la inclusión de otros más afines con la política del Gobierno, en mayo de 1968 el libro se presentó en depósito precedido de una titubeante nota del censor eclesiástico [de Pamplona], un claro Nihil Obstat y de una alentadora carta de un Obispo [de Salamanca]. Algo que creó evidente malestar y planteó a algunos censores una disyuntiva ética, dado que no debemos oponernos a su difusión, facilitando así (en cuanto católicos) la literatura de 'despegue' de la Iglesia respecto al Régimen. Pero en cuanto leales servidores de la Administración Pública y de este mismo Régimen, no podemos tolerar la inclusión, en el libro, de ciertos pasajes.

Menos preocupados por semejantes dilemas morales, el ministro Fraga y el director general de Cultura Popular y Espectáculo, Carlos Robles Piquer, se pusieron en contacto con el arzobispo de Madrid y el obispo secretario de la Conferencia de Metropolitanos y, al examinar al [sic] libro, ambos coincidieron en la inconveniencia de su difusión y prometieron realizar algunas gestiones para lograr que la propia editorial desistiera de su propósito. Paralelamente, el director general mantuvo conversaciones en el mismo sentido con el autor y con los señores Ruiz-Giménez y Riaza Ballesteros, este último Consejero Delegado de la editorial, hasta que ésta, como resultado de estas gestiones, solicitó la anulación del depósito previo. Sin embargo, en septiembre presentó de nuevo el libro para su publicación introduciendo importantes modificaciones. Una vez más los informes de lectura fueron negativos y Robles Piquer, extrañado de que el autor aún insistiera en su publicación - evidentemente, ignora lo que se trae entre manoselevó denuncia al fiscal del Tribunal Supremo que, a su vez, remitió las actuaciones al TOP. Arbeloa fue absuelto, pero totalmente destruida la edición, ocasionando a Edicusa pérdidas por valor de 412.500 pesetas de la época ${ }^{42}$.

Ese mismo año el gobierno español respondió a los sucesos del mayo francés con un cordón sanitario de resultados más que dudosos ${ }^{43}$, y con una serie de medidas represivas culminadas en enero del año siguiente con la proclamación del estado de excepción en todo el territorio nacional y el restablecimiento de la censura previa. En noviembre de 1968 fueron secuestrados los libros de dos testigos de lo ocurrido en París: El poder está en la calle, del sociólogo Sergio Vilar, y La revolución de mayo, del jesuita Antonio Luis Marzal. Según la censura, el primero era una:

Relación de los acontecimientos que ensombrecieron y ensangrentaron el Mayo parisino. Enjuiciamiento de ellos desde la perspectiva de negar a Herbert Marcuse la paternidad ideológica del movimiento, trampa del neocapitalismo. Afirmación del papel esencial del proletariado como clase social revolucionaria, frente al 'folklore' revolucionario estudiantil, por bien intencionado que éste estuviera. Repudio total del sistema socialdemócrata al que se tacha de reformista y no revolucionario. Afirmación de la lucha de clases para su supresión. Patrocinio de un sistema socialista revolucionario con bagaje intelectual marxista. Libro totalmente inconveniente

\footnotetext{
41 Ésta y las siguientes citas en el expediente de censura 4190/68, AGA-SC, caja 18.959.

Documento del Archivo Rafael Martínez Alés, Madrid.

3 CISQUELLA, Georgina; ERVITI, José Luis y SOROLLA, José A., Diez años de represión cultural. La censura de libros durante la Ley de Prensa (1966-1976), Barcelona, Anagrama, 1977, pp. 64-65.
} 
tanto en su aspecto general como por su peligrosidad para el estamento universitario español. Como por otro lado es socialista revolucionario, la obra no debe difundirse $e^{44}$.

El TOP encontró motivos no sólo para secuestrar y destruir la edición del libro, sino incluso para condenar el 16 de marzo de 1970 a Marzal, defendido por Gregorio Peces-Barba, como responsable, en concepto de autor, de un delito de información peligrosa del artículo 165 bis b) en grado de frustración, a dos multas de veinticinco mil y cinco mil pesetas, considerando que exalta la violencia como norma de actuación para el logro de reivindicaciones sociales, ponderándose asimismo la finalidad política de la huelga en el planteamiento de las relaciones laborales ${ }^{45}$.

En diciembre de 1968 Edicusa depositaba La vocación de Manuel Azaña, de Juan Marichal, sustancialmente su prólogo a los tres primeros volúmenes de la edición mexicana de las obras completas del ex presidente de la República. Su moderación en el lenguaje no impidió que la censura lo estimara extremadamente peligroso por su falta de veracidad, ya que se hace una biografía completamente falsa de la actitud política de Azaña. El autor se esfuerza en presentarnos un Azaña completamente identificado con un sentimiento nacional y español y con un carácter antirrevolucionario. Azaña que ha sido un político nefasto en la vida española aparece en esta biografía como el único español capaz de salvar a su Patria. Además:

El libro, aun siendo su carácter histórico, carece totalmente de objetividad, siendo todo él una apología del sistema republicano y del personaje biografiado del que se llega a hacer un mito. Se pretende, incluso, proyectar a la actualidad la validez de las ideas políticas de Azaña. Dentro de este carácter general se vierten conceptos atentatorios y claras ofensas a las instituciones militares, al clero y a la institución monárquica; se elogia el regionalismo y se considera que conceder la autonomía a Cataluña respondería a realidades vitales de la historia de España. Se acusa al Alzamiento Nacional de responsabilidad de la violenta ruptura con los principios democráticos, poniéndose en entredicho la legitimidad del régimen actual ${ }^{46}$.

El 14 de diciembre Robles Piquer escribía una carta al ministro Fraga para anunciarle que han presentado a depósito el adjunto libro. Contiene los prólogos que ya conoces a las Obras Completas de Azaña y comunicarle que hemos de tomar una decisión el próximo lunes. Para mí es evidente que debemos secuestrar el libro y dar parte a los Tribunales, aunque reconocía que nada puede asegurarse respecto a la decisión de los Jueces, pues el libro tiene carácter histórico. Ante ese riesgo el director general optó por la vía directa: he advertido telefónicamente a Ruiz Jiménez [sic] y le he señalado algunas páginas. Conocía el propósito de publicar el libro, pero no lo ha leído. Me ha dicho que lo leerá el fin de semana y me llamará por teléfono el próximo lunes. También esta vez las gestiones ante Ruiz-Giménez darían buenos resultados, pues dos días después Edicusa solicitaba la anulación del depósito y la devolución de los seis ejemplares depositados del libro, que aún tardaría tres años en ver la luz.

En marzo de 1969 José María Riaza, en calidad de consejero-delegado, escribía una carta a los suscriptores notificándoles que el estado de excepción había provocado un considerable retraso en la distribución y venta del último número de la revista, preparado ya desde enero, así como la introducción obligatoria de numerosas modificaciones. Les informaba asimismo de veintiún libros y dos suplementos que estaban pendientes de autorización oficial, del secuestro de La Iglesia en España, ayer y mañana de Arbeloa, de Distensiones cristiano-marxistas, del padre Josep Dalmau, de La revolución de Mayo, de Antonio L. Marzal, y de El poder está en la calle, de Sergio Vilar. Entre todas las solicitudes de publicación sólo una, El cine en la crítica del método de Álvaro del Amo, había sido autorizada ${ }^{47}$.

\footnotetext{
44 Esta cita y las siguientes en el expediente de censura 9986/68, AGA-SC, caja 19.403.

Expediente 9629/68, AGA-SC, caja 19.377.

Esta cita y las siguientes en el expediente de censura 10882/68, AGA-SC, caja 19.474.

Carta del 18-III-1969; AGA-SC, caja 606.
} 
El quebranto económico que suponía semejante situación era evidente y puso en serio peligro la continuidad de la editorial, como deseaba el Ministerio de Información y Turismo en una estrategia a largo plazo. Sin embargo, el apoyo de los suscriptores, varios miles en toda España que recibían cartas como ésta sin que las autoridades pudieran evitarlo, funcionó y acabó adquiriendo el carácter de un compromiso político.

\section{CONCLUSIÓN}

El cambio cultural de los años sesenta y primeros setenta cumplió una función de puente entre las innegables transformaciones socioeconómicas de esos años -fueran éstas o no impulsadas por el autoritarismo tecnocrático- y la concienciación, el compromiso y el activismo político de grupos sociales cada vez más amplios. Ahí radica su mayor interés para los historiadores, en ser el eslabón perdido entre ambos factores, los estructurales y los de estrategia política, que durante mucho tiempo han centrado interpretaciones historiográficas distintas cuando no opuestas de la transición española. Y eso explica la atención que está recibiendo en los últimos años, con la aparición de numerosos títulos sobre la prensa y las editoriales durante el "segundo franquismo" y la transición ${ }^{48}$. No cabe duda de que el giro cultural ha llegado, si bien algo tarde, a los estudios sobre el franquismo, hasta hace poco tiempo un terreno acotado de la historia política pura y dura.

Cuadernos para el Diálogo, como Índice o aún antes Destino, o como las revistas católicas -iTú!', Signo, Aún, Boletín HOAC, Serra d'Or, El Ciervo- habían nacido en el seno del régimen, y sus respectivas evoluciones anunciaron sucesivos abandonos en los apoyos sociales de aquél. Ese origen tuvo un doble efecto nada contradictorio, aunque pudiera parecerlo a primera vista: esquivaron con mayor facilidad la censura y la represión al mismo tiempo, y precisamente, porque ponían más en evidencia las contradicciones y la descomposición de esas bases sociales del régimen, y por ello tenían una mayor repercusión tanto dentro como fuera del país. No sólo: ese hecho permitió el encuentro entre diferentes generaciones, entre los antiguos intelectuales falangistas y católicos de la victoria, trastocada en deseo de reconciliación y examen de conciencia tras su alejamiento del poder en 1956, y sus jóvenes alumnos en la universidad u otras iniciativas culturales.

Las revistas y editoriales se convirtieron así en lugares de sociabilidad intelectual, como siempre lo fueron en la historia del siglo XX, pero ahora con un campo de actuación mucho más extenso considerando el enorme vacío cultural dejado por la represión franquista. En ese desierto

48 Entre otros, FAULI, Josep y otros, Tele/Estel, Arreu, Oriflama, Canigo i Presència. Cinc revistes catalanes entre la dictadura i la transició, Barcelona, Col.legi de Periodistes de Catalunya, 1987; GELI, Carles y HUERTAS CLAVERÍA, Josep M., Las tres vidas de «Destino», Barcelona, Anagrama, 1991; GONZÁLEZ CASANOVA, José A. (ed.), La revista «El Ciervo». Historia y teoría de cuarenta años, Barcelona, Península, 1992; ALTED, Alicia y AUBERT, Paul, «Triunfo» en su época, Madrid, Casa de Velázquez-Ediciones Pléyades, 1995; FORCADELL, Carlos (coor.), «Andalán», 1972-1987. Los espejos de la memoria, Zaragoza, Ibercaja, 1997; VVAA, La fuerza de diálogo. Homenaje a Joaquín Ruiz-Giménez, Madrid, Alianza, 1997; PLATA, Gabriel, La razón romántica . La cultura política del progresismo español a través de «Triunfo» (1962-1975), Madrid, Biblioteca Nueva, 1999; FERRÉ, Carme, «Serra d'Or», 1959-1977: intellectualitat $i$ cultura resistents, Cabrera de Mar, Galerada, 2000; DE CABO, Isabel, La resistencia cultural bajo el franquismo. En torno a la revista «Destino» (1957-1961), Barcelona, Áltera, 2001; FORMENT, Albert, José Martínez: la epopeya de «Ruedo Ibérico», Barcelona, Anagrama, 2000, o SARRIÁ BUIL, Aránzazu, Cuadernos de Ruedo ibérico (1965-1979). Exilio, cultura de oposición y memoria histórica, Tesis inédita, 2001. Sobre las editoriales han aparecido recientemente algunos libros conmemorativos y de memorias, pero la línea más interesante para el "segundo franquismo" es la emprendida por investigaciones que las enmarcan en el proceso más general de cambio cultural, como la llevada a cabo por ROJAS, Francisco, "Una editorial para los nuevos tiempos: Ciencia Nueva, $1965-$ 1970”, en MUÑOZ SORO, Javier, Intelectuales y segundo franquismo, Historia del Presente, 5 (2005), pp. 103-120. 
las miradas se dirigían lejos y hacia todas las direcciones: la recuperación del patrimonio intelectual perdido, el estudio de la reciente historia nacional, la deslegitimación del franquismo tecnocrático, la denuncia de sus contradicciones, la defensa de la institucionalización política de las regiones, la reivindicación de los derechos humanos y de las libertades políticas y sindicales eran compatibles con la pasión revolucionaria, las lecturas marxistas y la lucha por la liberación individual en sintonía con la vitalidad de la nueva izquierda que recorría el mundo de una parte a otra. En ese caldo algo revuelto, donde convivían democracia y revolución, tolerancia y oposición, idealismo y pragmatismo se formaron las nuevas generaciones intelectuales que iban a copar el poder político, cultural y académico tras la muerte de Franco.

Cuadernos para el Diálogo y Edicusa no fueron sólo una cantera de políticos y altos cargos de la administración, una escuela de futuros profesores universitarios, periodistas, editores, escritores y demás figuras intelectuales. Fueron también la escuela de una buena parte de la sociedad, la más activa si se quiere, aunque ya no tan marcada como poco antes por las diferencias de clase. De manera que muchos jóvenes pudieron acceder a la cultura y/o satisfacer sus ansias de consumo cultural, a menudo pero no siempre antesala del compromiso político, con los nuevos productos lanzados al incipiente mercado neocapitalista español por editoriales como Edicusa. Y descubrir así que existía el Ché Guevara, el LSD, los tebeos, la ecología, el feminismo, el psicoanálisis, la Segunda República, Manuel Azaña, las guerras en el Tercer Mundo, el teatro del absurdo o el estructuralismo marxista. No poco de ese bagaje se perdería en la resaca revolucionaria de los años setenta, y si algunos recordarían los momentos de exaltación con desencantada nostalgia, otros tratarían de olvidarlos como un exceso de juventud. Pero del poso de esos años se ha alimentado hasta hoy, para bien y para mal, la democracia española.

\section{ANEXO 1: LOS SUPLEMENTOS, 1968-1973}

1. Jesús Aguirre, Gómez Caffarena, José María González Ruiz, Juan Luis Pintos, Eduardo Obregón, Armendáriz y Tomás de la Quadra, Mesa redonda sobre el ateísmo (1968).

2. José Félix Tezanos, El bachillerato, ¿para qué? (1968).

3. Antonio Lara, El apasionante mundo del tebeo (1968).

4. José Antonio González Casanova, Los derechos humanos (1968).

5. Eduardo Haro Tecglen, Roberto Mesa, Mariano Aguilar Navarro y Wilfred Burchet, Vietnam (1968).

6. Estudio Colectivo: España: realidad y política (1969).

7. Equipo Data, ¿Quién es quién en las Cortes (1969).

8. Antonio Fernández Alba, La ciudad. Aspectos críticos del entorno urbano (1969).

9. Valeriano Bozal, Arte de vanguardia. Un nuevo lenguaje (1970).

10. Luis García San Miguel, México. La revolución detenida (1970).

11. Javier Alfaya, Españoles bajo el III Reich (Recuerdos de un triángulo azul) (1970).

12. Enrique Ruiz García, América Latina: la explosión de los poderes tradicionales (1970).

13. -14. Maurici Serrahima, Joaquim Marco, M. Sanchis Guarner, J. Carreras Planas, Rafael Pradas, Joan Oliver, María Aurelia Capmany, Terenci Moix, Carles Miralles, Joan Antoni Bench, Frederic Roda, Albert Manent, Josep Verdura, Antoni Romero, Baltasar Porcel, Jaume Fabra y Jordi Rubió, Cultura catalana. Perspectiva 70 (1970).

14. -

15. Manuel Martín Serrano, Publicidad y sociedad de consumo en España (1970).

16. Emilio Lamo de Espinosa, Julián Besteiro (1970).

17. VVAA, Chile: el camino al socialismo (1970).

18. Enrique Barón, La civilización del automóvil (1971). 
19. Eduardo García Rico, Literatura y política. En torno al realismo español (1971).

20. Antonio Sánchez-Gijón, Ensayo sobre política exterior española (1971).

21. María Jiménez Bermejo, Sociología del trabajo de la mujer (1971).

22. J. Catalán Lafuente, M. Martínez Merino y C. García Arcones, La era de la destrucción: la degradación de la naturaleza (1971).

23. Alberto Míguez, La Comuna de París. Ensayo sobre un mito histórico (1971).

24. Hugo Neira, Perú: informe urgente (1971).

25. Ángel Fernández Sepúlveda y Óscar Alzaga, Las asociaciones políticas en España (1971).

26. Javier Alfaya, Valle-Inclán, viviente (1971).

27. -28. Lilí Álvarez, Concepción Borrguero, María Campo Alange, Elena Catena, Consuelo de la Gándara, María Jiménez, Carmen Pérez Seoane, Mary Salas y Pura Salas, Mujer y aceleración histórica (1971).

28. -

29. Guillermo Luis Díaz-Plaja, El turismo, ¿un falso «boom»? Introducción a la problemática socioeconómica del turismo en Baleares (1972).

30. Juan Maestre Alfonso, Bolivia. Anotaciones sobre un proceso revolucionario (1972).

31. Eduardo Martínez de Pisón, La destrucción del paisaje natural en España (1972).

32. Ramón Padilla y Joaquín Bollo, USA: guerras internas. Negros y puertorriqueños (1972).

33. Valeriano Bozal, Cultura y capitalismo (1972).

34. Juan Luis Iglesias Fuentes, Comunidad Económica Europea. Razones y ejemplos de los obstáculo para la admisión de España (1972).

35. Juan Pedro Quiñonero, Una lectura de Baroja (Del folletín al surrealismo) (1972).

36. Carlos García Valdés, La pena de muerte (1973).

37. Guillermo Luis Díaz-Plaja, Las élites españolas (1973).

38. Carlos Díaz, Tres biografías anarquistas (Proudhon-Bakunin-Kropotkin) (1973).

39. Angels Pascual, Del mito de la juventud a la realidad de los jóvenes (1973).

\section{ANEXO 2: LIBROS PUBLICADOS POR EDICUSA ENTRE 1965 Y 1975 (INCLUIDOS LOS NO AUTORIZADOS)}

1. José Luis L. Aranguren, Moral y sociedad. Introducción a la moral social española del siglo XIX (1965).

2. Pietro Paran, La democracia y sus razones (1965).

3. Juan Anlló Vázquez, El estado actual de la agricultura española (1965).

4. A. Francisco Carrillo de Albornoz, La libertad religiosa y el Concilio Vaticano II (1966).

5. VVAA, Comentarios de «Cuadernos para el Diálogo» al Esquema XIII (1966).

6. Elías Díaz, Estado de derecho y sociedad democrática (1966).

7. Ricardo Domenech, El teatro, hoy (1966).

8. Juan Anlló Vázquez, Estructura y problemas del campo español (1967).

9. Gumersindo Trujillo, El federalismo español (1967).

10. Habla la mujer. Resultado de un sondeo en la juventud femenina actual (1967).

11. Alberto Míguez, Galicia: éxodo y desarrollo (1967).

12. Pablo VI, Desarrollo de los pueblos (1967).

13. Manuel Tuñón de Lara, Historia y realidad del poder(1967).

14. Demetrio Casado, Perfiles del hambre (Prólogo de Josué de Castro) (1967).

15. Modesto Espinar, Una democracia para España (1967).

16. VVAA, Comentarios de «Cuadernos para el Diálogo» a la «Populorum Progressio» (1967). 
17. Heleno Saña Halcón, El capitalismo y el hombre (1967).

18. José Luis García Delgado y Arturo López Muñoz (seudónimo), Crecimiento y crisis del capitalismo español (1967).

19. José María Maravall, Trabajo y conflicto social (1968).

20. Antonio Menchaca, La URSS, hoy (1968, prohibido).

21. Francisco Pi y Margall, Las nacionalidades (1968).

22. Remigio Conde Salgado, Sociedad, Estado y Derecho en la filosofía marxista (1968).

23. Arturo López Muñoz, Crecimiento y crisis en el campo español (1968).

24. Salvador Espriu, La pell de brau (texto bilingüe) (1968).

25. François Miterrand, El golpe de Estado permanente (1968).

26. Luigi Fabbri, Los comunistas y la religión (1968).

27. Víctor Manuel Arbeloa, La Iglesia en España, ayer y mañana. De la II República al futuro (1968).

28. Mieczyxlaw Falkowski, Contribución socialista al desarrollo (1968).

29. Pedro Laín Entralgo, El problema de la Universidad (1968).

30. Valeriano Bozal, Juntas revolucionarias, manifiestos y proclamas de 1868 (1968).

31. Joaquín Ruiz-Giménez, El Concilio y los derechos del hombre (1968).

32. Tom Kerstiens y otros, El pueblo de Dios en marcha (1968).

33. Josep Meliá, Los mallorquines (1968).

34. Josep Dalmau, Distensiones cristiano marxistas (1968).

35. Félix Grande, Occidente, ficciones, yo (1968).

36. Antonio Luis Marzal, La revolución de mayo (1968).

37. Sergio Vilar, El poder está en la calle (1968).

38. Juan Marichal, La vocación de Manuel Azaña (1968).

39. Joan Brossa, Novela (1968).

40. Antoni Jutglar, Ideologías y clases en la España contemporánea (1808-1874). Tomo I (1969).

41. Theodore Draper, Abuso de poder (1969).

42. Mario Gozzini y otros, La muerte de Dios (1969).

43. Jean Lacouture, De Gaulle (1969).

44. Mario Zagari, El desafío europeo (1969).

45. Vicente Aguilera Cerni, El arte impugnado (1969).

46. Álvaro del Amo, El cine en la crítica del método (1969).

47. Pierre Frasen y otros, Hay un mañana para el sacerdote (1969).

48. Roberto Mesa, Informe sobre Vietnam (1969).

49. R. Coste, Evangelio y política (1969).

50. Robert Rouquette, Nueva cristiandad (1969).

51. Enrique Tierno Galván, La enseñanza primaria en España (1969).

52. Jacques M. Verges, Estrategia judicial (1969).

53. Javier Tusell, Sociología electoral de Madrid (1969).

54. Maurice Duverger, La Quinta República (1969).

55. Georges Gusdorf, Para qué la universidad (1969) .

56. J.P. Audet, Matrimonio y celibato (1969).

57. Fernand Leger, Funciones de la pintura (1969).

58. Ronald Segal, La guerra de razas (traducción de Inocencio Arias) (1969).

59. Mario Cuminetti y otros, El fin de la Iglesia como sociedad perfecta (1969).

60. Franco Crespi y otros, Proceso a la religión (1969).

61. Eloy Fernández Clemente, Educación y revolución en Joaquín Costa (1969). 
62. Miklos Molnar, El declive de la I Internacional (1969).

63. Javier Rupérez Rubio, Estado confesional y libertad religiosa (1969).

64. Juan Muñoz, Anuario económico de España (1969).

65. Amando de Miguel, Sociología de la vida cotidiana (1969).

66. Emilio Gilolmo y José Álvarez Junco, Los jacobinos (1969).

67. Imre Szabo y otros, Concepto socialista de los derechos humanos (1969).

68. Sidney Cohen, Historia del LSD (1969).

69. Theodor W. Adorno, Dialéctica negativa (1969).

70. Albert Memmi, El hombre dominado (1969).

71. Luc Goustine, El 10 de mayo (1969).

72. Luis García San Miguel, México, la revolución detenida (1969).

73. Andre Jacob, Tiempo y lenguaje (1969).

74. Jordi Solé-Tura, Catalanismo y revolución burguesa (1969).

75. Antoni Jutglar, Ideologías y clases en la España contemporánea (1874-1931). Tomo II (1969).

76. Alfonso Carlos Comín, Noticia de Andalucía (1969).

77. Georges Gurvitch, Teoría de las clases sociales. Concepto de las clases sociales (1969).

78. Celso Furtado, Obstáculos al desarrollo de América Latina (1969).

79. Werner Blumenberg, Carlos Marx en documentos propios y testimonios gráficos (1969).

80. Juan Velarde Fuentes, Veinticinco años de economía española (1969).

81. Jesús Aguirre, Sermones en España (1969).

82. Valeriano Bozal, Arte y sociedad en España (1970).

83. Manuel Fernández Areal, La libertad de prensa en España (1970).

84. Miguel Martínez Cuadrado y otros, Cambio social y modernización política. Anuario 1969 (1970).

85. Antonio Machado, Cultura y sociedad. Tomo I. Escritos en prosa (edición de Aurora de Albornoz) (1970).

86. Julián Besteiro: el problema de Marruecos y la guerra europea (edición de Emilio Lamo de Espinosa) (1970).

87. Celso Furtado, La hegemonía de los USA y América Latina (1971).

88. Antonio Machado, Literatura y arte. Tomo II. Escritos en prosa (1971).

89. E. Gibbon, Africa como conflicto. Las relaciones interafricanas (1971).

90. Miguel Martínez Cuadrado, Anuario político español (1971).

91. Juan Muñoz, Economía española 1969. Anuario (1971).

92. Juli Busquets, Introducción a la sociología de las nacionalidades (1971).

93. Javier Tusell, Las elecciones del Frente Popular. Tomo I (1971).

94. Javier Tusell, Las elecciones del Frente Popular. Tomo II (1971).

95. José Luis Abellán, La cultura en España. Ensayo para un diagnóstico (1971).

96. Andrés García de Blas y otros, La economía española. 1970 (1971).

97. Albert Memmi, Retrato del colonizado (1971).

98. José Corrales Egea, La novela española actual (1971).

99. Javier Herrero, Los orígenes del pensamiento reaccionario español (1971).

100. Roberto Mesa, Las revoluciones del Tercer Mundo (1971).

101. Francesc Vallverdú, Sociología y lengua de la literatura (1971).

102. Pierre Gascar, Rimbaud y la Comuna (1971).

103. Louis Millet, El estructuralismo como método (1972).

104. Rolf Hochhuth, Guerrillas (1972).

105. Antonio Fernández Alba, La crisis de la arquitectura española (1972). 
106. Miguel Herrero de Miñón, El principio monárquico (1972).

107. Jean Stavobinski, La relación crítica (1972).

108. Enrique Tierno Galván, Antología y biografía de Marx (1972).

109. Giuseppe Vacca, Ciencia, Estado y crítica de clase (1972).

110. Luis López Álvarez, Los comuneros (1972).

111. Santos Sanz Villanueva, Tendencias de la novela española actual (1972).

112. Gregorio Peces-Barba, Persona, Sociedad, Estado (1972).

113. Dos Passos, Ermeburg y otros, La España del siglo XX vista por extranjeros (prólogo y selección de F. Flores Arroyuelo) (1972).

114. Juan Muñoz, La economía española. 1971 (1972).

115. Juan José Morato, Líderes del movimiento obrero español. 1868-1921 (selección y notas de Víctor Manuel Arbeloa) (1972).

116. Juan Ferrando Badía, La I República española (Historia político parlamentaria de la República de 1873) (1972).

117. A. Cotanda Carballo, Canarias, región polémica (1972).

118. Renato Treves, La justicia en Italia (1972).

119. José Carlos Mainer, Literatura y pequeña burguesía en España (1972).

120. Jean-Louis Barraul, Rabelais (1972).

121. Luis Gómez Llorente, Aproximación a la historia del socialismo español (1972).

122. Pío Baroja, Escritos de juventud (prólogo y selección de Manuel Longares García) (1972).

123. Alonso Pintado Fuertes, La raya de Portugal (1972).

124. Antonio Machado, Decires y pensares filosóficos. Tomo III. Escritos en prosa (1972).

125. Antonio Machado, A la altura de las circunstancias. Tomo IV. Escritos en prosa (1972).

126. Carlos Moya, Burocracia y sociedad industrial (1972).

127. José Antonio Lacomba, Ensayos sobre el siglo Xx español (1973).

128. Manuel Alcalá Ruiz, Buñuel, cine e ideología (1973).

129. Ignacio Fernández de Castro, Reforma educativa y desarrollo capitalista: informe crítico de la Ley de Educación (1973).

130. Juan Ignacio Ferreras, Introducción a una sociología de la novela española del siglo XIX (1973).

131. Georges Gusdorf, ¿Para qué los profesores? (1973).

132. Juan Antonio Fernández Ordóñez, Arquitectura y represión. Seminario de prefabricación (1973).

133. Santiago Amón, Picasso (1973).

134. Manuel Pizar, Los hegelianos en España y otras notas críticas (1973).

135. Roger Garaudy, La alternativa (1973).

136. Ignacio Fernández de Castro, La fuerza del trabajo en España (1973).

137. Elías Díaz, La filosofía social del krausismo español (1973).

138. Jesús Jiménez Blanco, La objeción de conciencia en España (1973).

139. Jaime Vera, Ciencia y proletariado (prólogo y selección de Juan José Castillo) (1973).

140. M. Tuñón de Lara (ed.), Sociedad, politica y cultura en la España de los siglos XIX y XX (1973).

141. José María Desantes, El autocontrol de la actividad informativa (1973).

142. La economía española. 1973 (1973).

143. Carlos García Valdés, No a la pena de muerte (1973).

144. Roberto Mesa, Vietnam: treinta años de lucha por la liberación, 1943-73 (1973).

145. Emilio Lamo de Espinosa, Filosofía y política de Julián Besteiro (1973). 
146. Jacint Ros Hombravella, Josep María Huertas Clavería, y otros Capitalismo español: de la autarquía a la estabilización. Tomos I y II (1973).

147. José Cazorla, Problemas de estratificación social en España (1973).

148. Luis García San Miguel, De la sociedad aristocrática a la sociedad industrial en la España del siglo XIX (1974).

149. Guillermo García Pérez, La economía y los reaccionarios. La Inquisición y los economistas (1974).

150. Amando de Miguel, Yo, crítico (1974).

151. Luis Carandell y Barrenechea, La Andalucía de la Sierra (1974).

152. Lorenzo Villalonga Mas, Economía en 1940 (1974).

153. Javier Tusell, Historia de la democracia cristiana en España, Tomo I (1974).

154. Manuel Tuñón de Lara, Movimiento obrero, política y literatura española (1974).

155. Luis Guillermo Díaz-Plaja, La condición emigrante (1974).

156. Luis Núñez Ladeveze, Crítica del discurso literario (1974).

157. Robert Escarpit y otros, Hacia una sociología del hecho literario (1974).

158. Javier Fernández Lalcona, El idealismo político de Ortega y Gasset: un análisis sintético de la evolución de su filosofía política (1974).

159. Virgilio Zapatero, Fernando de los Ríos. Los problemas del socialismo democrático (1974).

160. Juan Antonio Hormigón, Teatro, realismo y cultura de masas (1974).

161. Luis Carandell y Eduardo Barrenechea, Portugal, sí (1974).

162. Elías Díaz, Pensamiento español (1939-1973) (1974).

163. Carlos Paris, La universidad española actual: posibilidades y frustraciones (1974).

164. Javier Tusell, Historia de la democracia cristiana en España, Tomo II (1974).

165. Amando de Miguel, Sexo, mujer y natalidad en España (1974).

166. Manuel Tuñón de Lara, Costa y Unamuno en la crisis de fin de siglo (1974).

167. Alfonso Carlos Comín y Ángel García-Nieto, Juventud obrera y conciencia de clase. El proceso migratorio (1974).

168. Vidal y Gil, y otros, Estudios sobre el País Valenciano (1974).

169. Alejandra Ferrándiz y Vicente Verdú, Noviazgo y matrimonio en la burguesía española (1974).

170. José Juan Toharia, Cambio social y vida jurídica en España (1974).

171. Roberto Mesa, La rebelión colonial (1974).

172. Francisco J. Laporta, Política y sociología en la crisis del liberalismo español (1974).

173. Renato Treves, El juez y la sociedad: una investigación sociológica sobre la administración de justicia en Italia (estudio preliminar de Elías Díaz; traducción de Francisco J. Laporta y Ángel Zaragoza) (1974).

174. Salustiano del Campo, Política demográfica en España (1974).

175. Manuel Vázquez Montalbán, La penetración americana en España (1974).

176. José Manuel de Allendesalazar, El 98 de los americanos (1974).

177. Carlos García Barrón, Cancionero del 98 (1974).

178. Ángel Zaragoza Reverte, Abogacía y política (1975).

179. Antonio Gramsci, Cartas desde la cárcel (1975).

180. José Luis García Delgado, La economía española. 1974 (1975).

181. Ignacio Sotelo, Cuatro ensayos de historia de España (1975).

182. José Luis Abellán, La industria cultural en España (1975).

183. Juan Francisco Marsal, La sombra del poder (intelectuales y política en España, Argentina y México) (1975).

184. José Luis García Delgado, Los orígenes y el desarrollo del capitalismo español (1975).

185. Juan Antonio Ramírez, El «comic» femenino en España. Arte «sub» y anulación (1975). 